Article

\title{
Green Supplier Evaluation and Selection Using Cloud Model Theory and the QUALIFLEX Method
}

\author{
Ke-Qin Wang ${ }^{1}$, Hu-Chen Liu ${ }^{2, *}$, Liping Liu ${ }^{3}$ and Jia Huang ${ }^{2}$ \\ 1 School of Management, Northwestern Polytechnical University, Xi'an 710072, China; \\ keqinwang@nwpu.edu.cn \\ 2 School of Management, Shanghai University, Shanghai 200444, China; jiahuangshu@foxmail.com \\ 3 Business School, Nanjing Normal University, Nanjing 210023, China; lpliu1016@163.com \\ * Correspondence: huchenliu@foxmail.com; Tel.: +86-21-6613-3703; Fax: +86-21-6613-7931
}

Academic Editor: Andrea Appolloni

Received: 24 January 2017; Accepted: 24 April 2017; Published: 27 April 2017

\begin{abstract}
Nowadays, companies have to improve their practices in the management of green supply chain with increased awareness of environmental issues worldwide. Selecting the optimum green supplier is crucial for green supply chain management, which is a challenging multi-criteria decision making (MCDM) problem. Moreover, while evaluating the performance of alternative suppliers, decision makers tend to determine their assessments using linguistic descriptors due to experts' vague knowledge and information deficiency. Therefore, this paper develops an integrated MCDM model based on the cloud model and QUALIFLEX (qualitative flexible multiple criteria method) approach to assess the green performance of companies under economic and environmental criteria. For the introduced model, the linguistic terms, expressed in normal clouds, are utilized to assess alternatives against each selection criterion. A linear programming model is established to compute the weights of criteria with unknown or incompletely known weight information. An extended QUALIFLEX approach is proposed and used to select the most suitable green supplier. Finally, the proposed green supplier selection method is demonstrated by an empirical example of an auto manufacturer to confirm its rationality and effectiveness.
\end{abstract}

Keywords: green supply chain management; supplier selection; cloud model; QUALIFLEX approach

\section{Introduction}

Currently, companies, particularly in the developing nations, have to enhance the effectiveness of their green supply chain management activities to survive in the global marketplace. On the one hand, governments are paying more attention to environmental issues and have issued a series of environmental regulations due to diminishing raw materials, increasing levels of pollution, and deterioration of the environment. Besides, a variety of pressures from consumers are making companies more cautious with regards to the detrimental influences of their businesses operations on the environment [1]. In this regard, numerous green supplier development programs, such as green purchasing, design for environment, and reverse logistics, have been invested by organizations to enhance their green performance with respect to the supply chain [2,3]. According to [4], green supply chain management is an approach to the philosophy of management taking environmental concern into account in the supply chain management, which consists of product design, raw material extraction, production processes, product transportation as well as disposing of the end-of-life product. Given the increasing awareness of environmental protection, it is more significant for companies to conduct green supply chain management practices to minimize or eliminate the negative environmental effects of their business operations. In recent years, green supply chain management has received increasing interest among both academics and practitioners [4-6]. 
Within green supply chain management, organizations are required to assess the green performance of their suppliers and select the most appropriate one(s) in different stages of product life cycle [7]. Green supplier selection is a challenging multi-dimensional issue in the competitive environment $[8,9]$, which can be resolved by multi-criteria decision making (MCDM) methods. The QUALIFLEX (qualitative flexible multiple criteria method) [10] is an efficient outranking MCDM method that assesses all possible rankings of considered alternatives and finds the optimum one by using the maximum concordance/discordance index. The salient features of the QUALIFLEX method, compared to other MCDM methods, are that: (1) It can simultaneously deal with cardinal and ordinal information in the decision process; (2) It can perfectly address the complex decision making problems with numerous criteria and limited alternatives; (3) It does not require complicated computations in the multiple criteria decision analysis. Moreover, the use of the QUALIFLEX for green supplier selection is practical and has demonstrated satisfactory results [11-13]. Therefore, it is natural to utilize the QUALIFLEX approach to manage the green supplier selection problems involving comprehensive criteria.

On the other hand, in the process of green supplier evaluation, decision makers may have difficulty in evaluating candidate companies with specific numerical values due to the uncertainty of input data, and in particular, the vagueness of human thinking. As is stressed by many researchers [14,15], it is natural for decision makers to determine their judgments based on linguistic expressions, i.e., inexact and unquantifiable information, in real-life green supplier selection problems. Computing with words is the key to transforming linguistic variables into quantitative values, and the current methods of dealing with linguistic information can be mainly classified into three types, i.e., the linguistic computational model based on membership functions [16], the linguistic symbolic model based on ordinal scales [17] and the 2-tuple linguistic model [18]. However, as indicated by Wang et al. [19], the linguistic symbolic model and the 2-tuple linguistic model cannot produce a clearer description of either fuzziness or randomness of qualitative information. The linguistic computational model can describe fuzziness but not randomness. However, the cloud model [20] not only describes the fuzziness and randomness of linguistic terms but also makes the transformation between quantitative values and qualitative concepts much easier and interchangeable. In this way, the cloud model is of great value in solving the linguistic green supplier evaluation problems.

Based on the discussions above, this article is aimed at proposing an integrated decision support framework based on cloud model theory and the QUALIFLEX method for the evaluation of qualified green suppliers within a linguistic environment. The main contributions of this study are summarized as follows: First, the cloud model is introduced for the purpose of handling the fuzziness and randomness of linguistic expressions provided by decision makers. Second, we create an optimization model to obtain the criteria weights that are supposed to be totally unknown or incompletely known. Third, an extended QUALIFLEX algorithm is developed to prioritize the performance of different alternative suppliers and recommend the optimal one(s) for cooperation. In addition, the feasibility and effectiveness of the proposed green supplier selection approach are indicated by a case example concerning an automobile manufacturing company. The remaining part of this article is structured as below: Section 2 reviews the related literature of green supplier selection, the cloud model theory and the QUALIFLEX method. Section 3 introduces some basic concepts related to cloud model theory. In Section 4, we propose the green supplier selection approach using the cloud model and QUALIFLEX method. In Section 5, an illustrative example is presented to demonstrate the developed approach, and the solution results are compared with those derived by other existing methods. Finally, in Section 6, the conclusions and directions for future work complete the paper.

\section{Related Literature}

\subsection{Green Supplier Selection Methods}

To seek solutions for complex green supplier selection problems, an abundance of decision-making tools, especially those based on MCDM models, has been developed in the literature. For example, 
Uygun and Dede [15] proposed a comprehensive MCDM model using fuzzy decision-making trial and evaluation laboratory (DEMATEL), fuzzy analytical network process (ANP) and fuzzy technique for order preference based on similarity to ideal solution (TOPSIS) methods for assessing companies' green supply chain management performance. Wang et al. [21] proposed an integrated MCDM method by combining fuzzy AHP with fuzzy TOPSIS for selecting green suppliers in line with the economic and environmental criteria. Banaeian et al. [8] applied three fuzzy MCDM approaches, i.e., fuzzy TOPSIS, fuzzy VIKOR (VlseKriterijuska Optimizacija I Komoromisno Resenje) and fuzzy grey relational analysis (GRA), for green supplier evaluation and selection in the agri-food industry. Tsui et al. [22] used a hybrid MCDM method with DEMATEL-based ANP (DANP) and PROMETHEE to appraise and improve the performance of green suppliers in the thin film transistor liquid crystal display industry. Liou et al. [23] suggested a hybrid MCDM approach on the basis of DANP and modified COPRAS-G (COmplex PRoportional ASsessment of alternatives with Grey relations) for ranking and improving suppliers in green supply chain management. Kannan et al. [14] reported a fuzzy axiomatic design-based methodology for green supplier selection and utilized it for a Singapore plastic manufacturing company, and Kannan et al. [24] applied the fuzzy TOPSIS approach to an electronics company in Brazil for green supplier evaluation in accordance with green supply chain management practices. Hashemi et al. [25] developed a combined MCDM approach using ANP and improved GRA to determine the optimal green supplier from economic and environmental aspects. Yazdani et al. [26] proposed an integrated green supplier selection framework in which DEMATEL was used to addresses the inter-relationships between customer requirements; quality function deployment was adopted to identify the relationship degree between criteria and customer requirements, and COPRAS was applied to prioritize and rank the alternative suppliers. Bakeshlou et al. [27] addressed the green supplier selection problem using a hybrid multi objective decision making algorithm in which fuzzy DEMATEL was used to understand the interrelationships among criteria; fuzzy ANP provided the criteria weights considering their dependencies. In addition, a systematic literature review on the MCDM-based green supplier evaluation and selection approaches can be found in [5].

\subsection{Applications of QUALIFLEX Method}

Over the past decades, researchers have extended the QUALIFLEX method to model and manage MCDM problems within different decision-making environments. For instance, Zhang [28] proposed a Pythagorean fuzzy QUALIFLEX model based on the closeness index-based method for hierarchical multiple criteria decision making in the Pythagorean fuzzy and interval-valued Pythagorean fuzzy contexts. Zhang [29] proposed two interval-valued hesitant fuzzy QUALIFLEX approaches using a likelihood-based comparison method to solve MCDM problems under the interval-valued hesitant fuzzy environment. Xue et al. [30] elaborated on a combined linguistic MCDM model integrating hesitant 2-tuple linguistic term sets and the QUALIFLEX method in order to deal with robot selection problems with incomplete information of criteria weights. Tian et al. [31] proposed a simplified neutrosophic linguistic QUALIFLEX approach for green product design selection considering risk attitudes of decision makers, and Tian et al. [32] proposed an extended QUALIFLEX approach with a likelihood-based comparison method to handle MCDM problems in the context of hesitant fuzzy linguistic information. Peng et al. [33] presented two cross entropy measures for probability multi-valued neutrosophic numbers and proposed a probability multi-valued neutrosophic QUALIFLEX method to address MCDM problems. Wang et al. [34] developed a likelihood-based QUALIFLEX model to deal with decision-making problems under the context of interval type-2 trapezoidal fuzzy sets. Chen [35] suggested an interval-valued intuitionistic fuzzy QUALIFLEX approach using likelihood-based comparison method to resolve MCDM issues. In addition, other meaningful extensions of the QUALIFLEX technique in previous studies include the interval-valued intuitionistic fuzzy QUALIFLEX [36], the interval type-2 fuzzy QUALIFLEX [37], and the hesitant trapezoidal fuzzy QUALIFLEX [38]. 


\subsection{Applications of Cloud Model Theory}

In recent years, the cloud model theory has attracted increasing attention and has been successfully applied in many fields. For example, Zhang et al. [39] developed a hybrid information fusion approach that integrates the cloud model, Dempster-Shafer evidence theory and Monte Carlo simulation for perceiving safety risk of buildings adjacent to tunneling excavations. Wu et al. [40] proposed a cloud model-based decision framework for low-speed wind farm site selection within a pure 2-tuple linguistic environment. Wang and Wang [41] reported an evolving Takagi-Sugeno approach based on aggregated trapezium clouds that could be used for anomaly detection in large datasets. Shi et al. [42] established an integrated decision-making model using the cloud model and MABAC method for assessing healthcare waste treatment technologies from a multiple stakeholder perspective. Based on the cloud model and combined weighting method, Cao et al. [43] developed an assessment model for the analysis of debris-flow hazard. In Zhang et al. [44], a trust evaluation method based on the cloud model is proposed to detect malicious nodes and ensure security in clustered wireless sensor networks. Li et al. [45] applied fuzzy AHP and the cloud model for energy utilization evaluation of carbon performance in public projects, and Zhao and Li [46] used the cloud model and fuzzy comprehensive evaluation method to evaluate the risk of ultra-high voltage projects. Furthermore, an uncertain linguistic group MCDM method and an interval-valued intuitionistic linguistic decision making method were proposed by Wang et al. [47] and Wang et al. [48], respectively, based on cloud model theory.

\section{Preliminaries}

\subsection{Cloud Model Theory}

The cloud model is a new cognition model defined by Li [20] to represent the uncertainty (fuzziness and randomness) of qualitative concepts. In this part, some basic concepts and operations related to cloud model theory are introduced.

Definition 1. Supposing a qualitative concept $T$ defined on a universe of discourse $U$, let $x, x \in U$ be a random realization of the concept $T$ and $\mu_{T}(x) \in[0,1]$ be the membership degree of $x$ belonging to $T$, which corresponds to a random number with a stable tendency. Then the distribution of $x$ in the universe $U$ is called a cloud and every $x$ is called a cloud drop [20].

Definition 2. The characteristics of a cloud y are depicted by three parameters: expectation Ex, entropy En and hyper entropy He. Here, Ex is the center value of the qualitative concept domain, En measures the randomness and fuzziness of the qualitative concept, and He reflects the dispersion degree of the cloud drops and the uncertainty of the membership function. Generally, a cloud can be denoted by $y=(E x, E n, H e)[20]$.

Definition 3. Consider any two normal clouds $\widetilde{y}_{1}=\left(E x_{1}, E n_{1}, H e_{1}\right)$ and $\widetilde{y}_{2}=\left(E x_{2}, E n_{2}, H e_{2}\right)$ in the domain $U$, the basic operations of normal clouds are defined as follows [19]:

(1) $\widetilde{y}_{1}+\widetilde{y}_{2}=\left(E x_{1}+E x_{2}, \sqrt{E n_{1}^{2}+E n_{2}^{2}}, \sqrt{H e_{1}^{2}+H e_{2}^{2}}\right)$,

(2) $\widetilde{y}_{1} \times \widetilde{y}_{2}=\left(E x_{1} E x_{2}, \sqrt{\left(E n_{1} E x_{2}\right)^{2}+\left(E n_{2} E x_{1}\right)^{2}}, \sqrt{\left(H e_{1} E x_{2}\right)^{2}+\left(H e_{2} E x_{1}\right)^{2}}\right)$,

(3) $\lambda \widetilde{y}_{1}=\left(\lambda E x_{1}, \sqrt{\lambda} E n_{1}, \sqrt{\lambda} H e_{1}\right), \lambda>0$,

(4) $\widetilde{y}_{1}^{\lambda}=\left(E x_{1}^{\lambda}, \sqrt{\lambda}\left(E x_{1}\right)^{\lambda-1} E n_{1}, \sqrt{\lambda}\left(E x_{1}\right)^{\lambda-1} H e_{1}\right), \lambda>0$. 
Definition 4. Let $\widetilde{y}_{i}=\left(E x_{i}, E n_{i}, H e_{i}\right)(i=1,2, \ldots, n)$ be $n$ normal clouds in the universe of discourse $U$, and $w=\left(w_{1}, w_{2}, \ldots, w_{n}\right)^{T}$ be their associated weights with $w_{i} \in[0,1]$ and $\sum_{i=1}^{n} w_{i}=1$, then the cloud weighted averaging (CWA) is defined as [19]:

$$
\begin{aligned}
\mathrm{CWA}_{w}\left(\widetilde{y}_{1}, \widetilde{y}_{2}, \ldots, \widetilde{y}_{n}\right) & =\sum_{i=1}^{n} w_{i} \widetilde{y}_{i}=\sum_{i=1}^{n} w_{i}\left(E x_{i}, E n_{i}, H e_{i}\right) \\
& =\left(\sum_{i=1}^{n} w_{i} E x_{i}, \sqrt{\sum_{i=1}^{n} w_{i} E n_{i}^{2}}, \sqrt{\sum_{i=1}^{n} w_{i} H e_{i}^{2}}\right) .
\end{aligned}
$$

Definition 5. Let $\widetilde{y}_{1}=\left(E x_{1}, E n_{1}, H e_{1}\right)$ and $\widetilde{y}_{2}=\left(E x_{2}, E n_{2}, H e_{2}\right)$ be two arbitrary normal clouds in the domain $U$, then the distance between them is computed by [47]:

$$
d\left(\widetilde{y}_{1}, \widetilde{y}_{2}\right)=\left|\left(1-\frac{\left(E n_{1}+H e_{1}\right)}{E x_{1}}\right) E x_{1}-\left(1-\frac{\left(E n_{2}+H e_{2}\right)}{E x_{2}}\right) E x_{2}\right| .
$$

Definition 6. Let $\widetilde{y}=(E x, E n, H e)$ be a normal cloud in the domain $U$, then the signed distance of $\widetilde{y}$ from the origin $\widetilde{0}$ is determined by

$$
d(\widetilde{y}, \widetilde{0})=\left(1-\frac{(E n+H e)}{E x}\right) E x
$$

Note that the signed distances from normal clouds to $\widetilde{0}$ are real numbers, which satisfy the law of trichotomy.

Definition 7. Let $\widetilde{y}_{1}=\left(E x_{1}, E n_{1}, H e_{1}\right)$ and $\widetilde{y}_{2}=\left(E x_{2}, E n_{2}, H e_{2}\right)$ be two normal clouds in the domain $U$. Then the signed distance-based comparison of normal clouds is defined as follows:

(1) If $d\left(\widetilde{y}_{1}, \widetilde{0}\right)>d\left(\widetilde{y}_{2}, \widetilde{0}\right)$, then $\widetilde{y}_{1}$ is better than $\widetilde{y}_{2}$, i.e., $\widetilde{y}_{1}>\widetilde{y}_{2}$;

(2) If $d\left(\widetilde{y}_{1}, \widetilde{0}\right)<d\left(\widetilde{y}_{2}, \widetilde{0}\right)$, then $\widetilde{y}_{1}$ is worse than $\widetilde{y}_{2}$, i.e., $\widetilde{y}_{1}<\widetilde{y}_{2}$;

(3) If $d\left(\widetilde{y}_{1}, \widetilde{0}\right)=d\left(\widetilde{y}_{2}, \widetilde{0}\right)$, then $\widetilde{y}_{1}$ is indifferent to $\widetilde{y}_{2}$, i.e., $\widetilde{y}_{1}=\widetilde{y}_{2}$.

Definition 8. Let $\widetilde{y}_{i}=\left(E x_{i}, E n_{i}, H e_{i}\right)(i=1,2, \ldots, n)$ be a set of normal clouds in the universe of discourse $U$, and $\omega=\left(\omega_{1}, \omega_{2}, \ldots, \omega_{n}\right)$ be an associated weight vector satisfying $\omega_{j} \in[0,1]$ and $\sum_{j=1}^{n} \omega_{j}=1$, then the cloud ordered weighted averaging (COWA) is computed by [19]:

$$
\begin{aligned}
& \operatorname{COWA}_{\omega}\left(\widetilde{y}_{1}, \widetilde{y}_{2}, \ldots, \widetilde{y}_{n}\right)=\sum_{j=1}^{n} \omega_{j} \widetilde{y}_{\sigma(j)} \\
& =\left(\sum_{j=1}^{n} \omega_{j} E x_{\sigma(j)}, \sqrt{\sum_{j=1}^{n} \omega_{j} E n_{\sigma(j)}^{2}} \sqrt{\sum_{j=1}^{n} \omega_{j} H e_{\sigma(j)}^{2}}\right),
\end{aligned}
$$

where $\widetilde{y}_{\sigma(j)}=\left(E x_{\sigma(j)}, E n_{\sigma(j)}, H e_{\sigma(j)}\right)$ is the $j$ th largest element of $\widetilde{y}_{i}(i=1,2, \ldots, n)$.

\subsection{Laplace Distribution-Based Method}

Defining the aggregation weight vector $\omega$ is one key issue in the theory of the ordered weighted averaging (OWA) operator [49]. Recently, Mohammed et al. [50] developed a new method based on the Laplace distribution to calculate the OWA weight vector. This method has the ability to reduce the effect of "false" or "biased" opinions on the decision-making results by assigning higher weights to the median elements of the ordered arguments and lower weights to the tail elements. 
Definition 9. According to the argument-dependent method based on Laplace distribution, the associated weighting vector of the OWA operator is obtained by [50]:

$$
\omega_{j}=\frac{\frac{1}{2 \lambda_{n}} e^{-\frac{\left|i-\mu_{n}\right|}{\lambda_{n}}}}{\sum_{j=1}^{n} \frac{1}{2 \lambda_{n}} e^{-\frac{\left|i-\mu_{n}\right|}{\lambda_{n}}}}=\frac{e^{-\frac{\left|i-\mu_{n}\right|}{\lambda_{n}}}}{\sum_{j=1}^{n} e^{-\frac{\left|i-\mu_{n}\right|}{\lambda_{n}}}}, j=1,2, \ldots, n,
$$

where $n$ is the number of aggregated arguments, $\mu_{n}$ is the mean of the number of the argument, and $\lambda_{n}$ is the scale of the Laplace distribution. The parameter $\mu_{n}$ is calculated by

$$
\mu_{n}=\frac{1}{n} \frac{n(1+n)}{2}=\frac{1+n}{2},
$$

and the Laplace distribution standard deviation $\sigma_{n}$ is defined as

$$
\sigma_{n}=\sqrt{2} \lambda_{n}=\sqrt{\frac{1}{n} \sum_{j=1}^{n}\left(j-\mu_{n}\right)^{2}} .
$$

\section{The Proposed Green Supplier Selection Methodology}

Green supply chain management has become a challenging issue for companies to maintain their competitive positions due to the increased public concern of environmental issues and stricter governmental regulations. In this section, we introduce a novel decision support framework by combining the cloud model and QUALIFLEX method for addressing the green supplier selection problem with unknown or incomplete weight information. In a nutshell, the proposed methodology to select the optimum green supplier is comprised of three phases: assessing the performance of green suppliers based on normal clouds, acquiring the weights of evaluation criteria by a linear programming model, and determining the ranking orders of alternatives with the QUALIFLEX method. The procedure of the proposed green supplier selection approach is depicted in Figure 1, and the detailed explanations are presented as below.

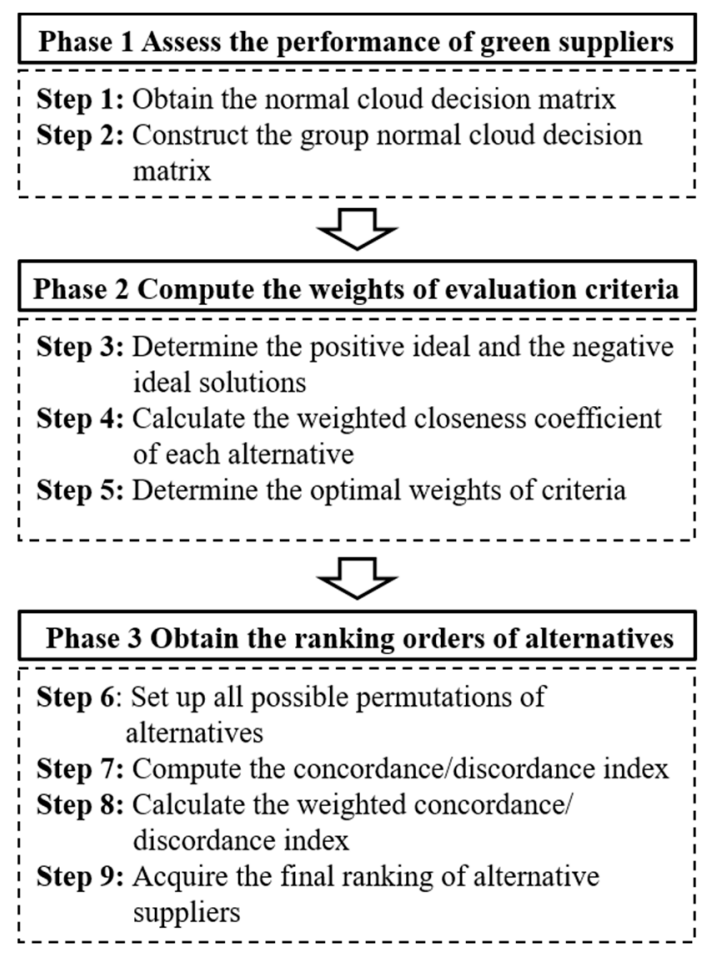

Figure 1. Flowchart of the proposed green supplier selection approach. 


\subsection{Assess the Performance of Green Suppliers}

Assume a green supplier selection problem with $m$ feasible alternatives $\left(\mathrm{A}_{i}, i=1,2, \ldots, m\right)$, which are assessed by a committee of $l$ decision makers $\left(\mathrm{DM}_{k}, k=1,2, \ldots, l\right)$ on the basis of $n$ evaluation criteria $\left(\mathrm{C}_{j}, j=1,2, \ldots, n\right)$. Let $D^{k}=\left[d_{i j}^{k}\right]_{m \times n}$ be the linguistic decision matrix, where $d_{i j}^{k}$ is the suitability assessment of alternative $\mathrm{A}_{i}$ versus criterion $C_{j}$ provided by the decision maker $\mathrm{DM}_{k}$. Next, the cloud model theory is used to model the linguistic evaluations on alternatives given by the decision makers. Step 1: Obtain the normal cloud decision matrix $X^{k}$

As discussed before, the cloud model theory is very practical for depicting the fuzziness and randomness of decision-making problems. Accordingly, the proposed green supplier selection approach utilizes the linguistic terms represented by normal clouds to assess the performance of alternative suppliers regarding various selection criteria. For instance, these linguistic terms can be represented by the normal clouds shown in Table 1.

Table 1. Linguistic ratings for alternative suppliers.

\begin{tabular}{cc}
\hline Linguistic Terms & Normal Clouds \\
\hline Very Poor (VP) & $(1,0.45,0.05)$ \\
Poor (P) & $(2,0.45,0.05)$ \\
Medium Poor (MP) & $(3,0.45,0.05)$ \\
Fair (F) & $(5,0.45,0.05)$ \\
Medium Good (MG) & $(6,0.45,0.05)$ \\
Good (G) & $(8,0.45,0.05)$ \\
Very Good (VG) & $(9,0.45,0.05)$ \\
\hline
\end{tabular}

Based on the linguistic ratings of each decision maker, the first step is to transform them into normal clouds as per the linguistic scale information to obtain the normal cloud decision matrix $X^{k}=\left[x_{i j}^{k}\right]_{m \times n}$, where $\widetilde{x}_{i j}=\left(E x_{i j}, E n_{i j}, H e_{i j}\right), i=1,2, \ldots, m ; j=1,2, \ldots, n$.

Step 2: Establish the group normal cloud decision matrix $\widetilde{X}$

Normally, there may exist "false" or "biased" judgements in the green supplier selection practice; that is to say, some decision makers may give excessively high or excessively low ratings to their preferred or repugnant suppliers. To deal with such cases, the COWA operator is adopted to combine the decision makers' performance assessments into representative group assessments.

By applying the COWA operator, the aggregation of individual cloud matrices $X^{k}=\left[x_{i j}^{k}\right]_{m \times n}(k=1,2, \ldots, l)$ is performed to construct the group normal cloud decision matrix $\widetilde{X}=\left[\widetilde{x}_{i j}\right]_{m \times n^{\prime}}$,i.e.,

$$
\begin{aligned}
\widetilde{x}_{i j} & =\operatorname{COWA}\left(\widetilde{x}_{i j}^{1}, \widetilde{x}_{i j}^{2}, \ldots, \widetilde{x}_{i j}^{l}\right)=\sum_{h=1}^{l} \omega_{j} \widetilde{x}_{i j}^{\sigma(h)} \\
& =\left(\sum_{h=1}^{l} \omega_{j} E x_{i j}^{\sigma(h)}, \sqrt{\sum_{h=1}^{l} \omega_{j}\left(E n_{i j}^{\sigma(h)}\right)^{2}}, \sqrt{\sum_{h=1}^{l} \omega_{j}\left(H e_{i j}^{\sigma(h)}\right)^{2}}\right),
\end{aligned}
$$

where $\widetilde{x}_{i j}^{\sigma(h)}=\left(E x_{i j}^{\sigma(h)}, E n_{i j}^{\sigma(h)}, H e_{i j}^{\sigma(h)}\right)$ is the $h$ th largest element of $x_{i j}^{k}=\left(E x_{i j^{\prime}}^{k} E n_{i j}^{k}, H e_{i j}^{k}\right)$ $(k=1,2, \ldots, l)$.

\subsection{Compute the Weights of Evaluation Criteria}

It is common that in the green supplier selection problems, the information concerning criteria weights may be completely unknown or partially known. Thus, it is very interesting and important to focus on this issue. The TOPSIS proposed by Hwang and Yoon [51] is a classical MCDM technique, which selects the most suitable alternative with the shortest distance from the positive-ideal solution 
and the farthest distance from the negative-ideal solution. The aim of this stage is to build an optimization model following the idea of the TOPSIS method for obtaining the criteria weights objectively. Suppose $w=\left(w_{1}, w_{2}, \ldots, w_{n}\right)^{T}$ is the weight vector of the criteria $C_{j}(j=1,2, \ldots, n)$, which is unknown a priori. In the following section, the detail processes of determining criteria weights are presented.

Step 3: Define the positive-ideal and the negative-ideal solutions

Within the cloud environment, the positive-ideal and the negative-ideal solutions, denoted as $A^{+}$ and $A^{-}$, can be respectively denoted by

$$
\begin{aligned}
& A^{+}=\left[\widetilde{x}_{j}^{+}\right]_{1 \times n}=\left\{\begin{array}{l}
\max _{i} \widetilde{x}_{i j} \text { for benefit criteria } \\
\min _{i} \widetilde{x}_{i j} \text { for cost criteria }
\end{array},\right. \\
& A^{-}=\left[\widetilde{x}_{j}^{-}\right]_{1 \times n}=\left\{\begin{array}{l}
\min _{i} \widetilde{x}_{i j} \text { for benefit criteria } \\
\max _{i} \widetilde{x}_{i j} \text { for cos t criteria }
\end{array} .\right.
\end{aligned}
$$

Step 4: Determine the weighted closeness coefficients of alternatives

By using Equation (11), the closeness coefficient of each alternative against the criteria is computed as follows:

$$
D_{i j}=\frac{d\left(\widetilde{x}_{i j}, \widetilde{x}_{j}^{-}\right)}{d\left(\widetilde{x}_{i j}, \widetilde{x}_{j}^{+}\right)+d\left(\widetilde{x}_{i j}, \widetilde{x}_{j}^{-}\right)}, i=1,2, \ldots, m, j=1,2, \ldots, n,
$$

where $d\left(\widetilde{x}_{i j}, \widetilde{x}_{j}^{+}\right)\left(d\left(\widetilde{x}_{i j}, \widetilde{x}_{j}^{-}\right)\right)$is the distance of $\mathrm{A}_{i}$ from $A^{+}\left(A^{-}\right)$concerning the criterion $\mathrm{C}_{j}$.

Then the weighted closeness coefficient of alternatives $\mathrm{A}_{i}$ is determined by

$$
D_{i}=\sum_{j=1}^{n} w_{j} D_{i j}=\sum_{j=1}^{n} w_{j} \frac{d\left(\widetilde{x}_{i j}, \widetilde{x}_{j}^{-}\right)}{d\left(\widetilde{x}_{i j}, \widetilde{x}_{j}^{+}\right)+d\left(\widetilde{x}_{i j}, \widetilde{x}_{j}^{-}\right)}, i=1,2, \ldots, m .
$$

Step 5: Calculate the optimal weights of criteria

The weighted closeness coefficient $D_{j}$ represents the relative closeness of alternative $\mathrm{A}_{i}$ to the ideal solution, that is, the larger the value of $D_{j}$, the better the alternative. Considering all the $m$ alternatives as a whole, the following linear programming model can be created for obtaining the criteria weights when the weight information is completely unknown:

$$
\begin{aligned}
& \max D(w)=\sum_{i=1}^{m} D_{i}=\sum_{i=1}^{m} \sum_{j=1}^{n} w_{j} D_{i j} \\
& \text { s.t. }\left\{\begin{array}{l}
\sum_{j=1}^{n} w_{j}=1, \\
w_{j} \geq 0, j=1,2, \ldots, n .
\end{array}\right.
\end{aligned}
$$

By resolving the above model, the optimal solutions are normalized to obtain the weights of criteria as

$$
w_{j}=\frac{\sum_{i=1}^{m} D_{i j}}{\sum_{j=1}^{n} \sum_{i=1}^{m} D_{i j}} .
$$

Furthermore, there are still some cases where the information regarding criteria weights is identified partially. The obtained weight information normally consists of the following five structural forms [52,53], for $i \neq j$ : (1) A weak ranking: $H_{1}=\left\{w_{i} \geq w_{j}\right\}$; (2) A strict ranking: $H_{2}=\left\{w_{i}-w_{j} \geq \beta_{j}\right\}\left(\beta_{j}>0\right)$; (3) A ranking of differences: $H_{3}=\left\{w_{i}-w_{j} \geq w_{k}-w_{l}\right\}$ 
$(j \neq k \neq l)$; (4) A ranking with multiples: $H_{4}=\left\{w_{i} \geq \beta_{j} w_{j}\right\}\left(0 \leq \beta_{j} \leq 1\right)$; (5) An interval form: $H_{5}=\left\{\beta_{i} \leq w_{i} \leq \beta_{i}+\varepsilon_{i}\right\}\left(0 \leq \beta_{i} \leq \beta_{i}+\varepsilon_{i}\right)$. For the sake of convenience, $H$ is assumed to be a set of recognized weight information and $H=H_{1} \cup H_{2} \cup H_{3} \cup H_{4} \cup H_{5}$. For these situations, the single objective optimization model in Equation (15) can be established.

$$
\begin{gathered}
\max D(w)=\sum_{i=1}^{m} D_{i}=\sum_{i=1}^{m} \sum_{j=1}^{n} w_{j} D_{i j} \\
(\mathrm{M}-2) \begin{array}{l}
w \in H, \\
\sum_{j=1}^{n} w_{j}=1, w_{j} \geq 0, j=1,2, \ldots, n .
\end{array}
\end{gathered}
$$

By executing model $(\mathrm{M}-2)$ with Lingo software, the optimal criteria weights can be obtained as $w=\left(w_{1}, w_{2}, \ldots, w_{n}\right)^{T}$.

\subsection{Determine the Ranking Orders of Alternatives}

Green supplier selection requires multi-dimensional techniques, and the QUALIFLEX method [10] is a pragmatic and reliable outranking MCDM technique to rank and select alternatives. Thus, in the third phrase of our proposed framework, we extend the classical QUALIFLEX approach to the cloud setting in order to determine the best suppliers. To sum up, the proposed cloud QUALIFLEX for the generation of ranking of green suppliers includes the following steps:

Step 6: Set up all possible permutations of alternatives

For the $m$ alternatives $\mathrm{A}_{i}(i=1,2, \ldots, m), m$ ! permutations of the ranking orders of alternatives exist. Assume that the $\rho$ th permutation denoted by $P_{\rho}$ is defined as:

$$
P_{\rho}=\left(\ldots, \mathrm{A}_{\chi}, \ldots, \mathrm{A}_{\eta}, \ldots\right), \rho=1,2, \ldots, m !,
$$

where $\mathrm{A}_{\xi}$ and $\mathrm{A}_{\zeta}, \xi, \zeta=1,2, \ldots, m$, are the suppliers under consideration, and $\mathrm{A}_{\xi}$ is ranked larger than or equal to $A_{\zeta}$.

Step 7: Acquire the concordance/discordance index

We use the following formula to compute the concordance/discordance index $\phi_{j}^{\rho}\left(\mathrm{A}_{\tilde{\zeta}}, \mathrm{A}_{\zeta}\right)$ in the $\rho$ th permutation against the criterion $C_{j}$ for each pair of alternatives $\left(A_{\tilde{\zeta}}, A_{\zeta}\right)$.

$$
\phi_{j}^{\rho}\left(\mathrm{A}_{\tilde{\zeta}}, \mathrm{A}_{\zeta}\right)=d\left(\widetilde{r}_{\tilde{\zeta} j}, \widetilde{0}\right)-d\left(\widetilde{r}_{\zeta j}, \widetilde{0}\right), j=1,2, \ldots, n .
$$

According to the comparison method of normal clouds introduced in Definition 7, $\phi_{j}^{\rho}\left(\mathrm{A}_{\xi}, \mathrm{A}_{\zeta}\right)>0$, $\phi_{j}^{\rho}\left(\mathrm{A}_{\tilde{\zeta}}, \mathrm{A}_{\zeta}\right)<0$, and $\phi_{j}^{\rho}\left(\mathrm{A}_{\tilde{\zeta}}, \mathrm{A}_{\zeta}\right)=0$ represent concordance, discordance and ex aequo, respectively. Step 8: Determine the weighted concordance/discordance index

Using the weight vector of criteria $w=\left(w_{1}, w_{2}, \ldots, w_{n}\right)^{T}$ acquired in the second stage, the weighted concordance/discordance index $\phi^{\rho}\left(\mathrm{A}_{\tilde{\xi}}, \mathrm{A}_{\zeta}\right)$ is determined by Equation (18) for the alternatives $\left(\mathrm{A}_{\tilde{\zeta}}, \mathrm{A}_{\zeta}\right)$ regarding permutation $P_{\rho}$.

$$
\phi^{\rho}\left(\mathrm{A}_{\tilde{\xi}}, \mathrm{A}_{\zeta}\right)=\sum_{j=1}^{n} \phi_{j}^{\rho}\left(\mathrm{A}_{\tilde{\zeta}}, \mathrm{A}_{\zeta}\right) w_{j}
$$

Step 9: Acquire the best ranking of alternative suppliers

For each permutation $P_{\rho}$, we obtain the comprehensive concordance/discordance index $\phi^{\rho}$ through Equation (19).

$$
\phi^{\rho}=\sum_{\xi, \zeta=1,2, \ldots, m} \sum_{j=1}^{n} \phi_{j}^{\rho}\left(\mathrm{A}_{\tilde{\zeta}}, \mathrm{A}_{\zeta}\right) w_{j} .
$$


A higher comprehensive concordance/discordance index value indicates that the ranking order of the alternatives is better. Hence, the optimum ranking of the considered suppliers can be identified via the comparison of the comprehensive concordance index values $\phi^{\rho}(\rho=1,2, \ldots, m !)$. That is, the permutation with the highest $\phi^{\rho}$ value, i.e., $P^{*}=\max _{\rho=1,2, \ldots, m !}\left\{\phi^{\rho}\right\}$ should be the final ranking of the alternatives.

\section{Illustrative Example}

Taking the green supplier selection for an auto manufacturing company as an example, the applicability and efficacy of the proposed green supplier evaluation model are demonstrated in this section.

\subsection{Background Description}

In this study, we consider an auto manufacturing company in Shanghai, China since the green initiatives are expected to be implemented within its operations. To comply with environmental regulations and adapt to social concerns, top management of this company decided to adjust its business strategy and become a company devoted to the public health and environment by committing itself to social responsibility. Currently, determination of the qualified green supplier for the automotive component, instrument panel, for improving the company's supply chain environmental performance is needed. An expert panel including five direct managers (denoted as DM1, DM2, .. , DM5) was established to rate three alternative companies, A1, A2 and A3.

Generally, various quantitative and qualitative evaluation criteria must be considered to determine the best green supplier. According to the literature surveys [5,6] and decision makers' opinions, green design, green purchasing, green production, green logistics and green recycling are determined as evaluation dimensions for the green supplier selection. Further, several related criteria of each dimension are identified for evaluating the alternative suppliers in more detail (see Figure 2). Then, the five decision makers are asked to rate each supplier with regard to the above criteria using the linguistic assessment terms shown in Table 1 . The completed assessment matrices provided by the expert group are presented in Table 2.

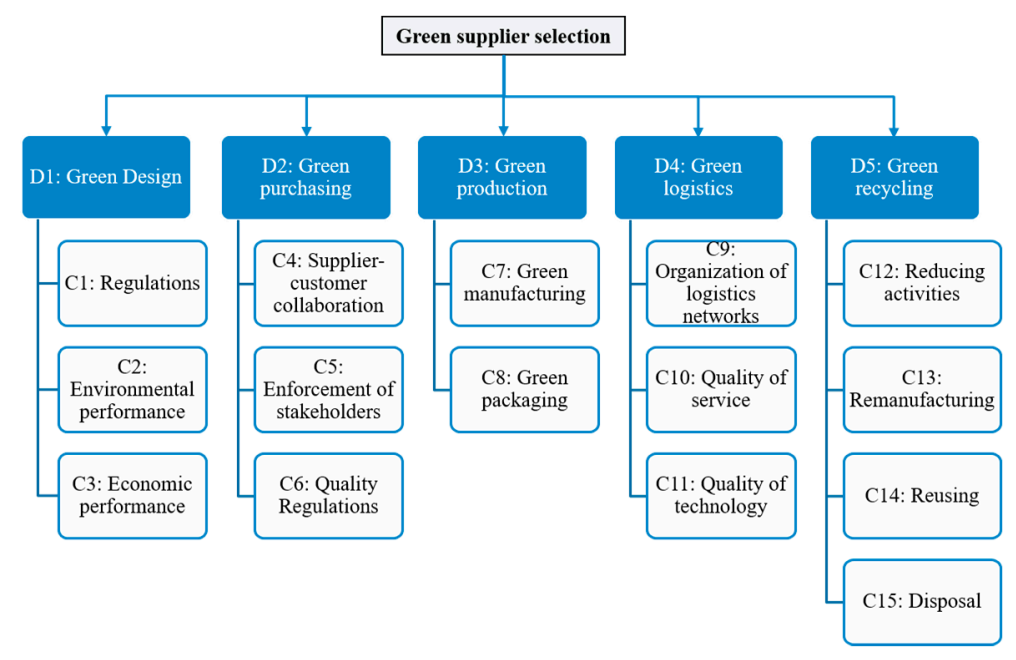

Figure 2. Dimensions and related criteria for green supplier selection. 
Table 2. Linguistic assessments of alternatives provided by the expert group.

\begin{tabular}{|c|c|c|c|c|c|c|c|c|c|c|c|c|c|c|c|c|}
\hline \multirow{2}{*}{$\begin{array}{l}\text { Decision } \\
\text { Makers }\end{array}$} & \multirow{2}{*}{ Alternatives } & \multicolumn{15}{|c|}{ Criteria } \\
\hline & & $\mathrm{C}_{1}$ & $\mathrm{C}_{2}$ & $C_{3}$ & $\mathrm{C}_{4}$ & $\mathrm{C}_{5}$ & $\mathrm{C}_{6}$ & $C_{7}$ & $\mathrm{C}_{8}$ & $\mathrm{C}_{9}$ & $\mathrm{C}_{10}$ & $\mathrm{C}_{11}$ & $C_{12}$ & $\mathrm{C}_{13}$ & $\mathrm{C}_{14}$ & $\mathrm{C}_{15}$ \\
\hline \multirow{3}{*}{$D M_{1}$} & $\mathrm{~A}_{1}$ & G & MP & VG & VP & $\mathrm{P}$ & $\mathrm{G}$ & $\mathrm{F}$ & $\mathrm{P}$ & MG & G & G & F & VG & $\mathrm{P}$ & G \\
\hline & $\mathrm{A}_{2}$ & $\mathrm{~F}$ & $\mathrm{P}$ & VG & $\mathrm{P}$ & VP & VG & VG & $\mathrm{P}$ & $\mathrm{P}$ & G & $\mathrm{F}$ & G & $\mathrm{F}$ & VP & $\mathrm{F}$ \\
\hline & $\mathrm{A}_{3}$ & $\mathrm{P}$ & MG & G & F & $\mathrm{F}$ & G & $\mathrm{F}$ & $\mathrm{P}$ & G & F & MP & MG & MG & $\mathrm{F}$ & G \\
\hline \multirow{3}{*}{$D M_{2}$} & $\mathrm{~A}_{1}$ & $G$ & MP & $G$ & $\mathrm{P}$ & $\mathrm{P}$ & VG & MG & $\mathrm{P}$ & $\mathrm{F}$ & VG & $F$ & MG & VG & MP & VG \\
\hline & $\mathrm{A}_{2}$ & MP & MP & MG & VP & MP & G & $\mathrm{G}$ & P & VP & G & MG & G & $\mathrm{F}$ & $\mathrm{P}$ & $\mathrm{F}$ \\
\hline & $A_{3}$ & $\mathrm{~F}$ & G & G & VP & MG & VG & VG & F & $\mathrm{F}$ & VG & MP & $\mathrm{F}$ & F & $\mathrm{F}$ & $\mathrm{P}$ \\
\hline \multirow{3}{*}{$D M_{3}$} & $\mathrm{~A}_{1}$ & G & F & G & VP & VP & VG & $F$ & MP & F & $G$ & $\mathrm{P}$ & $\mathrm{F}$ & VG & $\mathrm{P}$ & VG \\
\hline & $\mathrm{A}_{2}$ & MP & $\mathrm{P}$ & MG & $\mathrm{P}$ & $\mathrm{F}$ & VG & VG & VP & $\mathrm{P}$ & VG & $\mathrm{F}$ & MG & $\mathrm{F}$ & MP & MP \\
\hline & $\mathrm{A}_{3}$ & MP & MG & VG & MP & G & G & VG & MP & G & $\mathrm{P}$ & $\mathrm{F}$ & $\mathrm{F}$ & MP & MG & $\mathrm{F}$ \\
\hline \multirow{3}{*}{$D M_{4}$} & $\mathrm{~A}_{1}$ & G & MP & VG & VP & VP & $G$ & F & MP & G & $G$ & $\mathrm{~F}$ & MG & G & MP & VG \\
\hline & $\mathrm{A}_{2}$ & F & $\mathrm{P}$ & MG & $\mathrm{P}$ & VP & VG & G & VP & VP & VG & MG & G & $\mathrm{F}$ & VP & $\mathrm{F}$ \\
\hline & $\mathrm{A}_{3}$ & $\mathrm{~F}$ & G & MG & $\mathrm{F}$ & $\mathrm{F}$ & G & VG & MP & G & G & $\mathrm{P}$ & MG & $\mathrm{F}$ & $\mathrm{P}$ & $\mathrm{F}$ \\
\hline \multirow{3}{*}{$D M_{5}$} & $\mathrm{~A}_{1}$ & VG & MP & $\mathrm{G}$ & $P$ & $P$ & $G$ & MP & MG & VG & MG & MG & F & $G$ & VP & VG \\
\hline & $\mathrm{A}_{2}$ & $\mathrm{~F}$ & $\mathrm{P}$ & F & VP & VP & VG & VG & $\mathrm{P}$ & $\mathrm{P}$ & $\mathrm{G}$ & $\mathrm{G}$ & $\mathrm{F}$ & $\mathrm{F}$ & VP & $\mathrm{P}$ \\
\hline & $\mathrm{A}_{3}$ & $\mathrm{P}$ & MG & G & $\mathrm{P}$ & MG & VG & G & MG & G & F & F & MP & MP & G & $\mathrm{F}$ \\
\hline
\end{tabular}

\subsection{Application and Results}

The green supplier selection problem is solved by applying the proposed model and the implementation procedure is described as follows.

Step 1: Obtain the normal cloud decision matrix of each decision maker

The linguistic ratings of the five decision makers can be transformed into normal clouds easily based on Table 1 to construct the normal cloud decision matrixes $X^{k}=\left[x_{i j}^{k}\right]_{3 \times 15}(k=1,2, \ldots, 5)$.

Step 2: Establish the group normal cloud decision matrix $\widetilde{X}$

The produced normal cloud decision matrixes $X^{k}(k=1,2, \ldots, 5)$ are aggregated by using the COWA operator to establish the group cloud decision matrix $\widetilde{X}=\left[\widetilde{x}_{i j}\right]_{3 \times 15}$. The results obtained are presented in Table 3. Note that the weighting vector of the COWA operator is determined as $\omega=(0.068,0.183,0.498,0.183,0.068)$ with the Laplace distribution-based method.

Table 3. The group cloud decision matrix $\widetilde{X}$.

\begin{tabular}{cccccc}
\hline & $\mathbf{C}_{\mathbf{1}}$ & $\mathbf{C}_{\mathbf{2}}$ & $\mathrm{C}_{\mathbf{3}}$ & $\mathrm{C}_{\mathbf{4}}$ & $\mathrm{C}_{5}$ \\
\hline $\mathrm{A}_{1}$ & $(8.07,0.45,0.05)$ & $(3.14,0.45,0.05)$ & $(8.25,0.45,0.05)$ & $(1.25,0.45,0.05)$ & $(1.75,0.45,0.05)$ \\
$\mathrm{A}_{2}$ & $(4.50,0.45,0.05)$ & $(2.07,0.45,0.05)$ & $(6.14,0.45,0.05)$ & $(1.75,0.45,0.05)$ & $(1.64,0.45,0.05)$ \\
$\mathrm{A}_{3}$ & $(3.25,0.45,0.05)$ & $(6.50,0.45,0.05)$ & $(7.93,0.45,0.05)$ & $(3.18,0.45,0.05)$ & $(5.89,0.45,0.05)$ \\
$A^{+}$ & $(8.07,0.45,0.05)$ & $(6.50,0.45,0.05)$ & $(8.25,0.45,0.05)$ & $(3.18,0.45,0.05)$ & $(5.89,0.45,0.05)$ \\
$A^{-}$ & $(3.25,0.45,0.05)$ & $(2.07,0.45,0.05)$ & $(6.14,0.45,0.05)$ & $(1.25,0.45,0.05)$ & $(1.64,0.45,0.05)$ \\
\hline & $\mathrm{C}_{\mathbf{6}}$ & $\mathrm{C}_{\mathbf{7}}$ & $\mathrm{C}_{\mathbf{8}}$ & $\mathrm{C}_{\mathbf{9}}$ & $\mathrm{C}_{\mathbf{1 0}}$ \\
\hline $\mathrm{A}_{1}$ & $(8.25,0.45,0.05)$ & $(4.93,0.45,0.05)$ & $(2.95,0.45,0.05)$ & $(6.32,0.45,0.05)$ & $(7.93,0.45,0.05)$ \\
$\mathrm{A}_{2}$ & $(8.93,0.45,0.05)$ & $(8.75,0.45,0.05)$ & $(1.75,0.45,0.05)$ & $(1.75,0.45,0.05)$ & $(8.25,0.45,0.05)$ \\
$\mathrm{A}_{3}$ & $(8.25,0.45,0.05)$ & $(8.55,0.45,0.05)$ & $(3.50,0.45,0.05)$ & $(7.80,0.45,0.05)$ & $(5.62,0.45,0.05)$ \\
$A^{+}$ & $(8.93,0.45,0.05)$ & $(8.75,0.45,0.05)$ & $(3.50,0.45,0.05)$ & $(7.80,0.45,0.05)$ & $(8.25,0.45,0.05)$ \\
$A^{-}$ & $(8.25,0.45,0.05)$ & $(4.93,0.45,0.05)$ & $(1.75,0.45,0.05)$ & $(1.75,0.45,0.05)$ & $(5.62,0.45,0.05)$ \\
\hline & $\mathbf{C}_{\mathbf{1 1}}$ & $\mathbf{C}_{\mathbf{1 2}}$ & $\mathrm{C}_{\mathbf{1 3}}$ & $\mathbf{C}_{\mathbf{1 4}}$ & $\mathbf{C}_{\mathbf{1 5}}$ \\
\hline $\mathrm{A}_{1}$ & $(5.18,0.45,0.05)$ & $(5.25,0.45,0.05)$ & $(8.75,0.45,0.05)$ & $(2.18,0.45,0.05)$ & $(8.93,0.45,0.05)$ \\
$\mathrm{A}_{2}$ & $(5.89,0.45,0.05)$ & $(7.43,0.45,0.05)$ & $(5.00,0.45,0.05)$ & $(1.32,0.45,0.05)$ & $(4.43,0.45,0.05)$ \\
$\mathrm{A}_{3}$ & $(3.43,0.45,0.05)$ & $(5.12,0.45,0.05)$ & $(4.57,0.45,0.05)$ & $(5.18,0.45,0.05)$ & $(5.00,0.45,0.05)$ \\
$A^{+}$ & $(5.89,0.45,0.05)$ & $(7.43,0.45,0.05)$ & $(8.75,0.45,0.05)$ & $(5.18,0.45,0.05)$ & $(8.93,0.45,0.05)$ \\
$A^{-}$ & $(3.43,0.45,0.05)$ & $(5.12,0.45,0.05)$ & $(4.57,0.45,0.05)$ & $(1.32,0.45,0.05)$ & $(4.43,0.45,0.05)$ \\
\hline
\end{tabular}


Step 3: Define the positive-ideal and the negative-ideal solutions

Using Equations (9) and (10), the positive-ideal and the negative-ideal solutions $A^{+}$and $A^{-}$can be derived as listed in the last two rows of Table 3.

Step 4: Determine the weighted closeness coefficients of alternatives

The weighted closeness coefficient is calculated via Equations (11) and (12) for each alternative, and the results are as follows:

$$
\begin{aligned}
D_{1}= & w_{1}+0.241 w_{2}+w_{3}+0.026 w_{4}+0.687 w_{8}+0.756 w_{9}+0.879 w_{10} \\
& +0.714 w_{11}+0.059 w_{12}+w_{13}+0.224 w_{14}+w_{15} \\
D_{2}= & 0.259 w_{1}+0.258 w_{4}+w_{6}+w_{7}+w_{10}+w_{11}+w_{12}+0.104 w_{13} \\
D_{3}= & w_{2}+0.849 w_{3}+w_{4}+w_{5}+0.947 w_{7}+w_{8}+w_{9}+w_{14}+0.127 w_{15} .
\end{aligned}
$$

Step 5: Calculate the optimal weights of criteria

The weights of the fifteen criteria are acquired by Equation (14) as

$$
w=(0.06,0.059,0.088,0.06,0.049,0.047,0.092,0.08,0.083,0.089,0.081,0.05,0.052,0.058,0.053)^{T} .
$$

Step 6: Set up all possible permutations of alternatives

There are $6(=3 !)$ permutations of the rankings for the three potential green suppliers, i.e.,

$$
\begin{aligned}
& P_{1}=\left(A_{1}, A_{2}, A_{3}\right), P_{2}=\left(A_{1}, A_{3}, A_{2}\right), P_{3}=\left(A_{2}, A_{1}, A_{3}\right), \\
& P_{4}=\left(A_{2}, A_{3}, A_{1}\right), P_{5}=\left(A_{3}, A_{1}, A_{2}\right), P_{6}=\left(A_{3}, A_{2}, A_{1}\right) .
\end{aligned}
$$

Step 7: Acquire the concordance/discordance index

By using Equation (17), we can compute the concordance/discordance index $\phi_{j}^{\rho}\left(\mathrm{A}_{\bar{\xi}}, \mathrm{A}_{\zeta}\right)$ for each pair of suppliers $\left(\mathrm{A}_{\tilde{\xi}}, \mathrm{A}_{\zeta}\right)$ in the $\rho$ th permutation concerning every criterion $C_{j}$. For instance, the calculation results for the permutation $P_{1}$ are presented in Table 4 .

Table 4. The results of the concordance/discordance index for $P_{1}$.

\begin{tabular}{cccc}
\hline $\boldsymbol{P}_{\mathbf{1}}$ & $\boldsymbol{\phi}_{j}^{\mathbf{1}}\left(\mathbf{A}_{\mathbf{1}}, \mathbf{A}_{\mathbf{2}}\right)$ & $\boldsymbol{\phi}_{j}^{\mathbf{1}}\left(\mathbf{A}_{\mathbf{1}}, \mathbf{A}_{\mathbf{3}}\right)$ & $\boldsymbol{\phi}_{j}^{\mathbf{1}}\left(\mathbf{A}_{\mathbf{2}}, \mathbf{A}_{\mathbf{3}}\right)$ \\
\hline $\mathrm{C}_{1}$ & 3.570 & 4.817 & 1.247 \\
$\mathrm{C}_{2}$ & 1.068 & -3.366 & -4.434 \\
$\mathrm{C}_{3}$ & 2.115 & 0.319 & -1.796 \\
$\mathrm{C}_{4}$ & -0.498 & -1.932 & -1.434 \\
$\mathrm{C}_{5}$ & 0.111 & -4.136 & -4.247 \\
$\mathrm{C}_{6}$ & -0.681 & 0.000 & 0.681 \\
$\mathrm{C}_{7}$ & -3.817 & -3.613 & 0.204 \\
$\mathrm{C}_{8}$ & 1.204 & -0.549 & -1.753 \\
$\mathrm{C}_{9}$ & 4.570 & -1.477 & -6.047 \\
$\mathrm{C}_{10}$ & -0.319 & 2.315 & 2.634 \\
$\mathrm{C}_{11}$ & -0.702 & 1.749 & 2.451 \\
$\mathrm{C}_{12}$ & -2.179 & 0.136 & 2.315 \\
$\mathrm{C}_{13}$ & 3.749 & 4.183 & 0.434 \\
$\mathrm{C}_{14}$ & 0.864 & -3.000 & -3.864 \\
$\mathrm{C}_{15}$ & 4.502 & 3.932 & -0.570 \\
\hline
\end{tabular}

Step 8: Determine the weighted concordance/discordance index

The weighted concordance/discordance index $\phi^{\rho}\left(\mathrm{A}_{\tilde{\zeta}}, \mathrm{A}_{\zeta}\right)$ is acquired by employing Equation (18) for each pair of alternatives $\left(\mathrm{A}_{\xi}, \mathrm{A}_{\zeta}\right)(\xi, \zeta=1,2,3)$ and Table 5 shows the computational results.

Step 9: Acquire the best ranking of alternative suppliers 
Finally, the comprehensive concordance/discordance indexes $\phi^{\rho}(\rho=1,2, \ldots, 6)$ are determined by utilizing Equation (19) as follows:

$$
\phi^{1}=-0.178, \phi^{2}=1.640, \phi^{3}=-1.818, \phi^{4}=-1.640, \phi^{5}=1.818, \phi^{6}=0.178 .
$$

Based on the comprehensive concordance/discordance indexes $\phi^{\rho}(\rho=1,2, \ldots, 6)$, it is clear that $P^{*}=\max _{\rho=1,2, \ldots, 6}\left\{\phi^{\rho}\right\}=\phi^{5}$. Thereby, the optimal ranking of the three alternative companies is $A_{3}>A_{1}>A_{2}$, and the most appropriate green supplier is supplier $A_{3}$ for the vehicle manufacturer.

Table 5. The results of the weighted concordance/discordance indexes.

\begin{tabular}{cccccc}
\hline & $\boldsymbol{P}_{\mathbf{1}}$ & & $\boldsymbol{P}_{\mathbf{2}}$ & & $\boldsymbol{P}_{\mathbf{3}}$ \\
\hline$\phi^{1}\left(\mathrm{~A}_{1}, \mathrm{~A}_{2}\right)$ & 0.820 & $\phi^{2}\left(\mathrm{~A}_{1}, \mathrm{~A}_{3}\right)$ & -0.089 & $\phi^{3}\left(\mathrm{~A}_{2}, \mathrm{~A}_{1}\right)$ & -0.820 \\
$\phi^{1}\left(\mathrm{~A}_{1}, \mathrm{~A}_{3}\right)$ & -0.089 & $\phi^{2}\left(\mathrm{~A}_{1}, \mathrm{~A}_{2}\right)$ & 0.820 & $\phi^{3}\left(\mathrm{~A}_{2}, \mathrm{~A}_{3}\right)$ & -0.909 \\
$\phi^{1}\left(\mathrm{~A}_{2}, \mathrm{~A}_{3}\right)$ & -0.909 & $\phi^{2}\left(\mathrm{~A}_{3}, \mathrm{~A}_{2}\right)$ & 0.909 & $\phi^{3}\left(\mathrm{~A}_{1}, \mathrm{~A}_{3}\right)$ & -0.089 \\
\hline & $\boldsymbol{P}_{\mathbf{4}}$ & & $\boldsymbol{P}_{\mathbf{5}}$ & & $\boldsymbol{P}_{\mathbf{6}}$ \\
\hline$\phi^{4}\left(\mathrm{~A}_{2}, \mathrm{~A}_{3}\right)$ & -0.909 & $\phi^{5}\left(\mathrm{~A}_{3}, \mathrm{~A}_{1}\right)$ & 0.089 & $\phi^{6}\left(\mathrm{~A}_{3}, \mathrm{~A}_{2}\right)$ & 0.909 \\
$\phi^{4}\left(\mathrm{~A}_{2}, \mathrm{~A}_{1}\right)$ & -0.820 & $\phi^{5}\left(\mathrm{~A}_{3}, \mathrm{~A}_{2}\right)$ & 0.909 & $\phi^{6}\left(\mathrm{~A}_{3}, \mathrm{~A}_{1}\right)$ & 0.089 \\
$\phi^{4}\left(\mathrm{~A}_{3}, \mathrm{~A}_{1}\right)$ & 0.089 & $\phi^{5}\left(\mathrm{~A}_{1}, \mathrm{~A}_{2}\right)$ & 0.820 & $\phi^{6}\left(\mathrm{~A}_{2}, \mathrm{~A}_{1}\right)$ & -0.820 \\
\hline
\end{tabular}

\subsection{Discussion under Incomplete Weight Information}

The following is the situation where the weight information for the assessment criteria is incompletely known and the given weight information is as follows:

$$
H=\left\{\begin{array}{l}
w_{1} \leq 0.04, w_{2} \leq w_{1}, w_{3} \leq 0.03,0.1 \leq w_{4} \leq 0.13, w_{5} \geq 0.7 w_{4}, w_{6} \geq 0.05 \\
0.1 \leq w_{7} \leq 0.17,0.06 \leq w_{8} \leq 0.11, w_{4}-w_{9} \geq 0.02,0.06 \leq w_{8} \leq 0.10 \\
w_{10}=w_{11}, 0.008 \leq w_{12} \leq 0.012, w_{13} \leq 0.008, w_{13}=w_{14}, w_{15} \leq w_{13}
\end{array}\right\}
$$

Then, using Equations (9)-(12), the following linear programming model can be established:

$$
\begin{aligned}
& \max D(w)=1.2589 w_{1}+1.2409 w_{2}+1.8492 w_{3}+1.2578 w_{4}+1.0261 w_{5}+w_{6}+1.9466 w_{7} \\
& +1.6868 w_{8}+1.7557 w_{9}+1.8789 w_{10}+1.7136 w_{11}+1.0587 w_{12}+1.1038 w_{13} \\
& +1.2236 w_{14}+1.1266 w_{15} \\
& \text { s.t. }\left\{\begin{array}{l}
w \in H, \\
\sum_{j=1}^{15} w_{j}=1, w_{j} \geq 0, j=1,2, \ldots, 15 .
\end{array}\right.
\end{aligned}
$$

Based on the above model, the weight vector of the fifteen criteria is computed as

$$
w=(0.04,0.04,0.03,0.013,0.091,0.05,0.17,0.11,0.11,0.1,0.1,0.008,0.008,0.008,0.005)^{T} .
$$

Accordingly, the comprehensive concordance/discordance indexes $\phi^{\rho}(\rho=1,2, \ldots, 6)$ are computed as $\phi^{1}=-1.921, \phi^{2}=0.173, \phi^{3}=-2.094, \phi^{4}=-0.173, \phi^{5}=2.094, \phi^{6}=1.921$. Hence, the optimal priority order of the three alternative suppliers is $A_{3}>A_{1}>A_{2}$, which is exactly the same as the ranking result earlier. This implies that the proposed decision support framework is also useful for the green supplier selection problems when the criteria weight information is incompletely known.

\subsection{Comparative Study}

Next, a comparative analysis is conduced to show the effectiveness of our proposed decision support approach with respect to other green supplier selection methods. We base the analysis on the same case example and choose the fuzzy VIKOR [1], the fuzzy TOPSIS [15], the improved GRA [25] to 
facilitate the comparison analysis. The ranking results of the three alternatives determined by these methods are tabulated in Table 6.

Table 6. Ranking results of different methods.

\begin{tabular}{ccccc}
\hline Alternatives & Fuzzy VIKOR & Fuzzy TOPSIS & Improved GRA & The Proposed Method \\
\hline $\mathrm{A}_{1}$ & 2 & 2 & 2 & 2 \\
$\mathrm{~A}_{2}$ & 2 & 3 & 3 & 3 \\
$\mathrm{~A}_{3}$ & 1 & 1 & 1 & 1 \\
\hline
\end{tabular}

From the results of Table 6, it is easily seen that the most suitable green supplier for the considered application remains the same, i.e., $\mathrm{A}_{3}$, according to the proposed approach and the listed methods. Further, the ranking orders of the suppliers with the proposed approach are totally in agreement with the results acquired via the fuzzy TOPSIS and the improved GRA methods. This proves the validity of the proposed green supplier selection model. However, in comparison with the listed methods, the distinct advantages of the approach being proposed in this study are as below: (1) By using the cloud model theory, the proposed model effectively prevents the loss of information in the semantic transformation and also easily completes an interchangeable conversion between qualitative concepts and quantitative information; (2) The impact of "false" or "biased" assessments of decision makers on the decision result can be decreased by using the COWA operator in aggregating personal judgments into overall assessments; (3) Against the basic rule of the TOPSIS, the proposed model can be used to manage the green supplier selection problems where the weight information of criteria is completely unknown or partly identified; (4) With the aid of the extended QUALIFLEX algorithm, an accurate and credible ranking of available suppliers can be obtained. In particular, the proposed method is suitable for green supplier selection problems having a large number of criteria but limited alternatives.

\section{Conclusions}

In this study, we present a practical integrated MCDM framework based on the cloud model and QUALIFLEX method to assess and select the most appropriate green supplier considering both economic and environmental criteria. The cloud model is used for representing the linguistic assessments of decision makers with respect to alternative companies and an extension of the classical QUALIFLEX is applied to generate green supplier rankings. In addition, for the situations where the information of criteria weight is unknown or partly known previously, the proposed approach can derive the criteria weights by using a TOPSIS-based optimization model. The proposed green supplier selection method is validated with a real-life case company of the automobile manufacturing industry setup. The results show that our proposed framework is more expressive in capturing uncertainty and vagueness of decision makers' judgements and is very useful to yield the best green supplier in green supplier management.

Even with the advantages of our proposed approach, there are some limitations and room for further research. First, interactions of criteria are not considered in the proposed green supplier selection approach although, in some situations, various types of relationships may exist among criteria. In the future, the Choquet integral technique should be incorporated into the proposed model to analyze the inter-dependent effects between evaluation criteria. Second, the proposed method assumes that decision makers provide deterministic linguistic measurements on the alternative suppliers. In the real world, however, decision makers may use random variables to express their assessments owing to time limitations and the increasing complexity of green supplier selection problems. Thus, it is a promising direction to apply stochastic MCDM methods [54,55] for green supplier selection. In addition, considerable computations are involved in the proposed decision-making algorithm. Therefore, in future research, software can be developed so that manufacturers and service providers can apply the proposed approach conveniently to determine the most suitable one for cooperation. 
Acknowledgments: The authors are very grateful to the editor and reviewers for their insightful and constructive comments and suggestions, which are very helpful in improving the quality of the paper. This work was partially supported by the National Natural Science Foundation of China (Nos. 71671125 and 71402090), the Program for Professor of Special Appointment (Young Eastern Scholar) at Shanghai Institutions of Higher Learning (No. QD2015019), and the Ministry of Education Foundation of Humanities and Social Science (No. 12YJC630201).

Author Contributions: The individual contribution and responsibilities of the authors were as follows: Ke-Qin Wang and Hu-Chen Liu designed the research, Liping Liu and Jia Huang provided extensive advice throughout the study regarding the abstract, introduction, research design, research methodology, findings and revision of the manuscript. The discussion was a team task. All authors have read and approved the final manuscript.

Conflicts of Interest: The authors declare no conflict of interest.

\section{References}

1. Rostamzadeh, R.; Govindan, K.; Esmaeili, A.; Sabaghi, M. Application of fuzzy VIKOR for evaluation of green supply chain management practices. Ecol. Indic. 2015, 49, 188-203. [CrossRef]

2. Awasthi, A.; Kannan, G. Green supplier development program selection using NGT and VIKOR under fuzzy environment. Comput. Ind. Eng. 2016, 91, 100-108. [CrossRef]

3. Bai, C.; Sarkis, J. Green supplier development: Analytical evaluation using rough set theory. J. Clean. Prod. 2010, 18, 1200-1210. [CrossRef]

4. Srivastava, S.K. Green supply-chain management: A state-of-the-art literature review. Int. J. Manag. Rev. 2007, 9, 53-80. [CrossRef]

5. Govindan, K.; Rajendran, S.; Sarkis, J.; Murugesan, P. Multi criteria decision making approaches for green supplier evaluation and selection: A literature review. J. Clean. Prod. 2015, 98, 66-83. [CrossRef]

6. Igarashi, M.; de Boer, L.; Fet, A.M. What is required for greener supplier selection? A literature review and conceptual model development. J. Purch. Supply Manag. 2013, 19, 247-263. [CrossRef]

7. Bai, C.; Sarkis, J. Integrating sustainability into supplier selection with grey system and rough set methodologies. Int. J. Prod. Econ. 2010, 124, 252-264. [CrossRef]

8. Banaeian, N.; Mobli, H.; Fahimnia, B.; Nielsen, I.E.; Omid, M. Green supplier selection using fuzzy group decision making methods: A case study from the agri-food industry. Comput. Oper. Res. 2016. [CrossRef]

9. Sarkis, J.; Dhavale, D.G. Supplier selection for sustainable operations: A triple-bottom-line approach using a Bayesian framework. Int. J. Prod. Econ. 2015, 166, 177-191. [CrossRef]

10. Paelinck, J.H.P. Qualiflex: A flexible multiple-criteria method. Econ. Lett. 1978, 1, 193-197. [CrossRef]

11. Li, J.; Wang, J.Q. An extended QUALIFLEX method under probability hesitant fuzzy environment for selecting green suppliers. Int. J. Fuzzy Syst. 2017. [CrossRef]

12. Zhang, X.; Xu, Z.S. Hesitant fuzzy QUALIFLEX approach with a signed distance-based comparison method for multiple criteria decision analysis. Expert Syst. Appl. 2015, 42, 873-884. [CrossRef]

13. Peng, J.J.; Wang, J.Q.; Yang, W.E. A multi-valued neutrosophic qualitative flexible approach based on likelihood for multi-criteria decision-making problems. Int. J. Syst. Sci. 2017, 48, 425-435. [CrossRef]

14. Kannan, D.; Govindan, K.; Rajendran, S. Fuzzy axiomatic design approach based green supplier selection: A case study from Singapore. J. Clean. Prod. 2015, 96, 194-208. [CrossRef]

15. Uygun, Ö.; Dede, A. Performance evaluation of green supply chain management using integrated fuzzy multi-criteria decision making techniques. Comput. Ind. Eng. 2016, 102, 502-511. [CrossRef]

16. Zadeh, L.A. The concept of a linguistic variable and its application to approximate reasoning-I. Inf. Sci. 1975, 8, 199-249. [CrossRef]

17. $\mathrm{Xu}, \mathrm{Z}$.S. A method based on linguistic aggregation operators for group decision making with linguistic preference relations. Inf. Sci. 2004, 166, 19-30. [CrossRef]

18. Herrera, F.; Martínez, L. A 2-tuple fuzzy linguistic representation model for computing with words. IEEE Trans. Fuzzy Syst. 2000, 8, 746-752.

19. Wang, J.Q.; Peng, L.; Zhang, H.Y.; Chen, X.H. Method of multi-criteria group decision-making based on cloud aggregation operators with linguistic information. Inf. Sci. 2014, 274, 177-191. [CrossRef]

20. Li, D.Y.; Liu, C.Y.; Gan, W.Y. A new cognitive model: Cloud model. Int. J. Intell. Syst. 2009, 24, 357-375. [CrossRef] 
21. Wang Chen, H.M.; Chou, S.Y.; Luu, Q.D.; Yu, T.H.K. A fuzzy MCDM approach for green supplier selection from the economic and environmental aspects. Math. Probl. Eng. 2016, 2016. [CrossRef]

22. Tsui, C.W.; Tzeng, G.H.; Wen, U.P. A hybrid MCDM approach for improving the performance of green suppliers in the TFT-LCD industry. Int. J. Prod. Res. 2015, 53, 6436-6454. [CrossRef]

23. Liou, J.J.H.; Tamošaitienè, J.; Zavadskas, E.K.; Tzeng, G.H. New hybrid COPRAS-G MADM model for improving and selecting suppliers in green supply chain management. Int. J. Prod. Res. 2015, 54, 114-134. [CrossRef]

24. Kannan, D.; de Sousa Jabbour, A.B.L.; Jabbour, C.J.C. Selecting green suppliers based on GSCM practices: Using fuzzy TOPSIS applied to a Brazilian electronics company. Eur. J. Oper. Res. 2014, 233, 432-447. [CrossRef]

25. Hashemi, S.H.; Karimi, A.; Tavana, M. An integrated green supplier selection approach with analytic network process and improved grey relational analysis. Int. J. Prod. Econ. 2015, 159, 178-191. [CrossRef]

26. Yazdani, M.; Chatterjee, P.; Zavadskas, E.K.; Hashemkhani Zolfani, S. Integrated QFD-MCDM framework for green supplier selection. J. Clean. Prod. 2017, 142, 3728-3740. [CrossRef]

27. Bakeshlou, E.A.; Khamseh, A.A.; Asl, M.A.G.; Sadeghi, J.; Abbaszadeh, M. Evaluating a green supplier selection problem using a hybrid MODM algorithm. J. Intell. Manuf. 2017, 28, 913-927. [CrossRef]

28. Zhang, X. Multicriteria Pythagorean fuzzy decision analysis: A hierarchical QUALIFLEX approach with the closeness index-based ranking methods. Inf. Sci. 2016, 330, 104-124. [CrossRef]

29. Zhang, Z. Multi-criteria decision-making using interval-valued hesitant fuzzy QUALIFLEX methods based on a likelihood-based comparison approach. Neural Comput. Appl. 2016. [CrossRef]

30. Xue, Y.X.; You, J.X.; Zhao, X.; Liu, H.C. An integrated linguistic MCDM approach for robot evaluation and selection with incomplete weight information. Int. J. Prod. Res. 2016, 54, 5452-5467. [CrossRef]

31. Tian, Z.P.; Wang, J.; Wang, J.Q.; Zhang, H.Y. Simplified neutrosophic linguistic multi-criteria group decision-making approach to green product development. Group Decis. Negot. 2017, 26, 597-627. [CrossRef]

32. Tian, Z.P.; Wang, J.; Wang, J.Q.; Zhang, H.Y. A likelihood-based qualitative flexible approach with hesitant fuzzy linguistic information. Cogn. Comput. 2016, 8, 670-683. [CrossRef]

33. Peng, H.G.; Zhang, H.Y.; Wang, J.Q. Probability multi-valued neutrosophic sets and its application in multi-criteria group decision-making problems. Neural Comput. Appl. 2016. [CrossRef]

34. Wang, J.C.; Tsao, C.Y.; Chen, T.Y. A likelihood-based QUALIFLEX method with interval type-2 fuzzy sets for multiple criteria decision analysis. Soft Comput. 2015, 19, 2225-2243. [CrossRef]

35. Chen, T.Y. Interval-valued intuitionistic fuzzy QUALIFLEX method with a likelihood-based comparison approach for multiple criteria decision analysis. Inf. Sci. 2014, 261, 149-169. [CrossRef]

36. Chen, T.Y. Data construction process and QUALIFLEX-based method for multiple-criteria group decision making with interval-valued intuitionistic fuzzy sets. Int. J. Inf. Technol. Decis. Mak. 2013, 12, 425-467. [CrossRef]

37. Chen, T.Y.; Chang, C.H.; Rachel Lu, J.F. The extended QUALIFLEX method for multiple criteria decision analysis based on interval type-2 fuzzy sets and applications to medical decision making. Eur. J. Oper. Res. 2013, 226, 615-625. [CrossRef]

38. Zhang, X.; Xu, Z.; Liu, M. Hesitant trapezoidal fuzzy QUALIFLEX method and its application in the evaluation of green supply chain initiatives. Sustainability 2016, 8. [CrossRef]

39. Zhang, L.; Wu, X.; Zhu, H.; AbouRizk, S.M. Perceiving safety risk of buildings adjacent to tunneling excavation: An information fusion approach. Automat. Constr. 2017, 73, 88-101. [CrossRef]

40. Wu, Y.; Chen, K.; Zeng, B.; Yang, M.; Li, L.; Zhang, H. A cloud decision framework in pure 2-tuple linguistic setting and its application for low-speed wind farm site selection. J. Clean. Prod. 2017, 142, 2154-2165. [CrossRef]

41. Wang, M.X.; Wang, J.Q. An evolving Takagi-Sugeno model based on aggregated trapezium clouds for anomaly detection in large datasets. J. Intell. Fuzzy Syst. 2017, 32, 2295-2308. [CrossRef]

42. Shi, H.; Liu, H.C.; Li, P.; Xu, X.G. An integrated decision making approach for assessing healthcare waste treatment technologies from a multiple stakeholder. Waste Manag. 2017, 59, 508-517. [CrossRef] [PubMed]

43. Cao, C.; Xu, P.; Chen, J.; Zheng, L.; Niu, C. Hazard assessment of debris-flow along the baicha river in Heshigten Banner, Inner Mongolia, China. Int. J. Environ. Res. Public Health 2017, 14, 30. [CrossRef] [PubMed]

44. Zhang, T.; Yan, L.; Yang, Y. Trust evaluation method for clustered wireless sensor networks based on cloud model. Wirel. Netw. 2016. [CrossRef] 
45. Li, L.; Fan, F.; Ma, L.; Tang, Z. Energy utilization evaluation of carbon performance in public projects by FAHP and cloud model. Sustainability 2016, 8, 630. [CrossRef]

46. Zhao, H.; Li, N. Risk evaluation of a UHV power transmission construction project based on a cloud model and FCE method for sustainability. Sustainability 2015, 7, 2885-2914. [CrossRef]

47. Wang, J.Q.; Peng, J.J.; Zhang, H.Y.; Liu, T.; Chen, X.H. An uncertain linguistic multi-criteria group decision-making method based on a cloud model. Group Decis. Negot. 2015, 24, 171-192. [CrossRef]

48. Wang, J.Q.; Wang, P.; Wang, J.; Zhang, H.Y.; Chen, X.H. Atanassov's interval-valued intuitionistic linguistic multicriteria group decision-making method based on the trapezium cloud model. IEEE Trans. Fuzzy Syst. 2015, 23, 542-554. [CrossRef]

49. Yager, R.R. On ordered weighted averaging aggregation operators in multicriteria decisionmaking. IEEE Trans. Syst. Man Cybern. 1988, 18, 183-190. [CrossRef]

50. Mohammed, E.A.; Naugler, C.T.; Far, B.H. Breast tumor classification using a new OWA operator. Expert Syst. Appl. 2016, 61, 302-313. [CrossRef]

51. Hwang, C.L.; Yoon, K. Multiple Attributes Decision Making Methods and Applications; Springer: Berlin, Germany, 1981.

52. Zhang, X.; Xu, Z.S.; Wang, H. Heterogeneous multiple criteria group decision making with incomplete weight information: A deviation modeling approach. Inf. Fusion 2015, 25, 49-62. [CrossRef]

53. Liu, H.C.; You, J.X.; Li, P.; Su, Q. Failure mode and effect analysis under uncertainty: An integrated multiple criteria decision making approach. IEEE Trans. Reliab. 2016, 65, 1380-1392. [CrossRef]

54. Zhou, H.; Wang, J.Q.; Zhang, H.Y. Stochastic multicriteria decision-making approach based on SMAA-ELECTRE with extended gray numbers. Int. Trans. Oper. Res. 2017. [CrossRef]

55. Yu, S.M.; Wang, J.; Wang, J.Q. An interval type-2 fuzzy likelihood-based MABAC approach and its application in selecting hotels on a tourism website. Int. J. Fuzzy Syst. 2017, 19, 47-61. [CrossRef]

(C) 2017 by the authors. Licensee MDPI, Basel, Switzerland. This article is an open access article distributed under the terms and conditions of the Creative Commons Attribution (CC BY) license (http:/ / creativecommons.org/licenses/by/4.0/). 